in vivo $34: 3285-3289(2020)$

doi:10.21873/invivo.12166

\title{
Cocaine Reduces Ciliary Beat Frequency of Human Nasal Epithelial Cells
}

\author{
ALEXANDER NASTEV ${ }^{1}$, J. ULRICH SOMMER ${ }^{2}$, WIELAND BEHR ${ }^{1}$, BORIS A. STUCK ${ }^{1}$, C. EMIKA MUELLER $^{1}$, \\ ANGELA SCHELL ${ }^{3}$, BENEDIKT KRAMER ${ }^{3}$, DANIEL HAEUSSLER ${ }^{3}$, KARL HOERMANN $^{3}$ and RICHARD BIRK $^{1}$ \\ ${ }^{1}$ Department of Otorhinolaryngology, Head and Neck Surgery, \\ University Hospital Marburg, Philipps-Universität Marburg, Marburg, Germany; \\ ${ }^{2}$ Department of Otorhinolaryngology, Head and Neck Surgery, \\ Helios University Hospital Wuppertal, Wuppertal, Germany; \\ ${ }^{3}$ Department of Otorhinolaryngology, Head and Neck Surgery, University Hospital Mannheim, \\ Mannheim Medical Faculty, Ruprecht-Karls-Universität Heidelberg, Heidelberg, Germany
}

\begin{abstract}
Background/Aim: Cocaine is a widely used recreational drug and is known for its nasal complications including epithelial, cartilage and bone damage. The aim of the study was to analyze the impact of cocaine on ciliary beat frequency $(C B F)$ of human nasal epithelial cells and therefore better understand its side effects on nasal mucosa. Materials and Methods: Nasal epithelial cells of 21 healthy subjects were harvested and exposed in vitro to cocaine hydrochloride solutions ranging from $0.875 \%$ to $7 \%$. Highspeed video footage was acquired with phase contrast microscopy and CBF was analyzed with Sissons-Ammons Video Analysis (SAVA) software. Results: All tested concentrations led to a significant reduction in $C B F$ compared to the control. Effects increased over time and with concentration. A mechanical inhibition of cilia by cocaine crystals was also observed. Conclusion: We assume that $C B F$ reduction is part of the pathomechanism leading to nasal complications in cocaine abuse. Considering these results, clinical usage of cocaine should be critically evaluated and restricted to select cases only.
\end{abstract}

The leaves of the Erythroxylum coca plant have been chewed by the indigenous people of South America long before the first isolation of cocaine in 1855 by Friedrich Gaedcke was

This article is freely accessible online.

Correspondence to: Richard Birk, Department of Otorhinolaryngology Head and Neck Surgery, Philipps-Universität Marburg, Baldinger Straße, 35039 Marburg, Germany. Tel: +49 64215866478, Fax: +49 64215866367, e-mail: richard.birk@staff.uni-marburg.de

Key Words: Cocaine, ciliary beat frequency (CBF), human nasal epithelial cells. successful (1). By using it, the native South Americans could work longer and harder on the fields due to its stimulating effects and endure hunger for longer periods of time. In 1884, Carl Koller introduced cocaine as a local anesthetic in ophthalmology (2). At present, more potent anesthetic derivatives like lidocaine mostly replaced cocaine in the medical field (3). Various commercial products containing cocaine like beverages and cigarettes have been sold until the early $20^{\text {th }}$ century. Due to its addictive nature and long-term side-effects, cocaine became outlawed for public use in most countries. Still, it is predominantly used as a recreational drug until today.

The most common form is its water-soluble hydrochloride salt which can be swallowed, injected or sniffed. The effect of cocaine is based on the fact that $35-37 \%$ of applied cocaine is absorbed systemically by the nasal mucosa $(4,5)$. In 2017, approximately 18 million people world-wide consumed an average amount of 28,6 $\mathrm{g}$ of cocaine per year. Global cocaine use is still increasing and is centered in North America and Central and Western Europe (6).

Cocaine causes a local anesthesia by blocking sodium-ion channels in peripheral nerves and leads to euphoria and psychological addiction by blocking the reuptake of dopamin, serotonin and noradrenaline in the central nervous system (CNS) $(7,8)$. Its sympathomimetic effects cause an elevated blood pressure and can promote arrhythmia and sudden cardiac death (9). In approximately $5 \%$ of cocaine users, the nasal application leads to cocaine induced midline destructive lesions (CIMDL) including hyposmia, crusting, ulcers, nasal septal perforation and bone erosion of the palate, skull base, orbita and paranasal sinuses (10).

Different local and systemic factors are attributed to these complications: Locally, vasoconstriction, as well as mechanical and chemical trauma play their role by promoting bacterial infection and necrosis. Other systemic factors like osteoblast inhibition, immunosuppression and 
auto-antibody formation are suspected $(8,11,12)$. By influencing ciliary function, local harmful factors could be potentiated.

Mucociliary clearance (MC) ensures that the airways stay free of inhaled particles and detritus. A synchronous and fast ciliary beat, as well as the right amount and consistency of mucous is essential for a functioning MC (13-15). Disruption of ciliary function like in primary ciliary dyskinesia or change in mucous consistency like in cystic fibrosis lead to impaired MC and are associated with chronic, recurrent and more severe upper airway infections $(16,17)$. There are many factors influencing CBF. CBF naturally is reduced during sleep and with increasing age (18). Long-term alcohol and nicotine abuse lead to CBF reduction $(19,20)$.

Local defensins secreted by the mucosa provide an additional defense mechanism against pathogens. Prerequisite for sufficient defensin function is a specific environment provided by the mucous. Acidity leads to dysfunction (21). Cocaine hydrochloride (CHCL) has a pH of 3.44-5.37 (22).

There are only a few studies on the influence of cocaine on CBF. Photoelectrical CBF-analysis has shown $\mathrm{CBF}$ reduction for cocaine and other local anesthetics (23-25). Up to date, there is no study directly visualizing the effect of cocaine on the ciliary beat of nasal epithelial cells, which is the aim of this study.

\section{Materials and Methods}

The study was carried out in the Department of Otorhinolaryngology, Head and Neck surgery at the University Medical Centre Mannheim, Germany after approval was given by the ethics committee of the Medical Faculty Mannheim, University of Heidelberg (reference number: 2010-267n-MA). 21 subjects (11 female, 10 male) with an average age of 31.5 years ranging from 19 to 51 years have been included in the study. Subjects with rhinosinusitis, using topical nasal drugs and smokers were excluded. Written informed consent was obtained from all participants.

Samples of the nasal mucosa were harvested by brushing the middle nasal meatus with a cytology brush (Gynobrush Plus, Heinz Herenz, Germany).

Before harvesting the samples, the subjects were asked to blow their nose and anterior rhinoscopy was performed. Subjects with residual mucous and any signs of rhinitis where ruled out. After that, the brush was moistened with $0.9 \%$ saline solution and inserted in the wider middle nasal meatus where the epithelium was scraped by rotating and moving the brush back and forth. Immediately after brushing, the harvested cells were transferred into $5 \mathrm{ml}$ of RPMI medium (RPMI 1640, cell culture tested, standard, L-glutamine: $300 \mathrm{mg} / \mathrm{l}$, PromoCell, Heidelberg, Germany) and stored at room temperature.

Tests were performed 3-9 $\mathrm{h}$ after obtaining the cells, utilizing the plateau phase of the ciliary beat frequency in RPMI medium (26).

Solutions where created to achieve test concentrations of $7 \%$, $3.5 \%, 1.75 \%$ and $0.875 \%$ in the test medium by dissolving CHCL in RPMI medium. Unaltered RPMI medium was used as control (0\%).

The medium containing the harvested cells was split into five Petri dishes and put under a phase contrast microscope (Leica Microsystems $\mathrm{GmbH}$, Wetzlar, Germany) with 400-fold magnification.

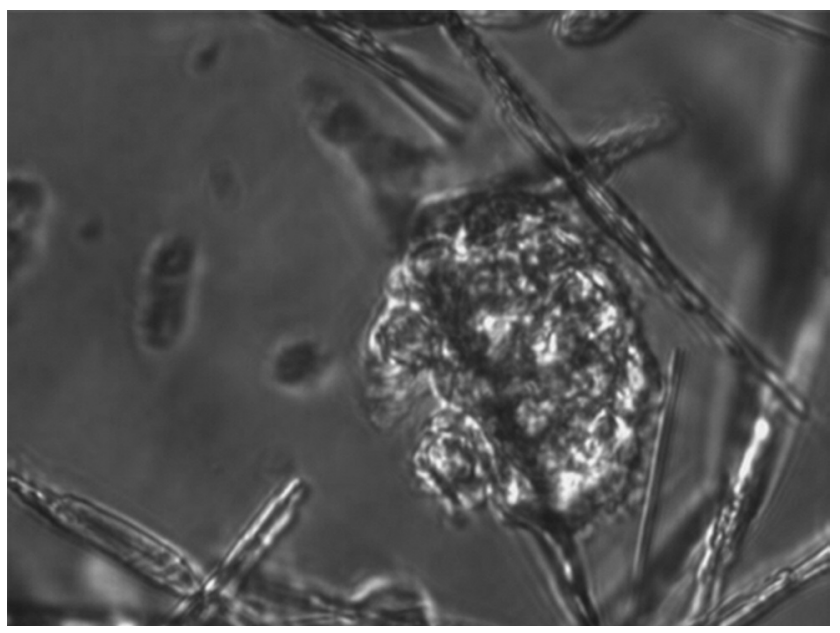

Figure 1. Phase contrast microscopy of cocaine crystals showing after $1 \mathrm{~min}$ in $3.5 \%$ cocaine hydrochloride solution and settling on nasal epithelial cell cluster (400-fold magnification).

After ensuring that each dish contained vital cell clusters with beating nasal cilia, the test medium was added. Immediately afterwards, a cell cluster was focused and videos were recorded every $60 \mathrm{~s}$ for $15 \mathrm{~min}$ using a high-speed video camera and the Sissons-Ammons Video Analysis (SAVA) software (19). Each sequence had a length of $2 \mathrm{~s}$ with a frame rate of 100/s. The starting point $\mathrm{t}=0$ was set at the beginning of the first video. Only intact cell clusters were selected, due to the fact that disrupted ciliated epithelial edges show significantly lower CBF (27).

Since the cell clusters were moved by the added media, it could take up to $30 \mathrm{~s}$ until video recording could be started. Because of this shift, baseline measurements before adding the test media were not comparable and a negative control was used instead. Using SAVA on the acquired videos, CBF was determined by selecting rectangular regions of interests (ROIs) containing ciliated cells. For each cell cluster, three different ROIs where specified and tracked over time.

\section{Results}

After analyzing all samples ( $\mathrm{n}=21)$, an instant inhibiting effect of CHCL on CBF could be shown. The effect increased with time and slightly with concentration. After 1 min, median CBF in $0.875 \% \mathrm{CHCL} / \mathrm{RPMI}$ solution was significantly lower than in RPMI only $(4.52 \pm 1.17 \mathrm{~Hz}$ vs. $8.09 \pm 1.85 \mathrm{~Hz} ; p=0.001)$. Further reduction of $\mathrm{CBF}$ over time was observed with an endpoint of $1.65 \pm 1.17 \mathrm{~Hz}$ at $\mathrm{t}=15 \mathrm{~min}$. $\mathrm{CBF}$ reduction at 5, 10 and 15 min was significantly lower compared to CBF in RPMI only ( $p=0.001)$. Similar observations were made for $1.75 \%$, $3.5 \%$ and $7 \%$ CHCL/RPMI solutions, showing a slight increase of overall $\mathrm{CBF}$ reduction with increasing concentration of CHCL. Crystal formation was observed in all test solutions, increasing with time and concentration, leading to a mechanical obstruction of the cilia (Figure 1). All Results are listed in Table I and a graphical visualization is provided in Figure 2. 
Nastev et al: Cocaine Reduces Ciliary Beat Frequency

Table I. Mean ciliary beat frequency (CBF) for the control group (0\%) and tested cocaine hydrochloride (CHCL) solutions with standard deviation (SD).

\begin{tabular}{lcccccccccc}
\hline Time & $\begin{array}{c}\text { Control } \\
\text { CHCL }\end{array}$ & SD & $\begin{array}{c}0.875 \% \\
\text { CHCL }\end{array}$ & SD & $\begin{array}{c}1.75 \% \\
\text { CHCL }\end{array}$ & SD & $\begin{array}{c}3.5 \% \\
\text { CHCL }\end{array}$ & SD & $\begin{array}{c}7 \% \\
\text { CHCL }\end{array}$ \\
\hline 0 & 8.05 & 2.33 & 3.09 & 1.09 & 4.37 & 1.39 & 4.18 & 1.84 & 3.55 & 2.17 \\
1 & 8.09 & 1.85 & 4.52 & 1.17 & 4.45 & 1.60 & 4.21 & 1.69 & 3.20 & 1.72 \\
5 & 7.26 & 1.48 & 3.66 & 1.26 & 3.48 & 1.31 & 3.28 & 1.39 & 2.34 & 1.31 \\
10 & 7.13 & 1.54 & 2.31 & 1.32 & 2.13 & 1.02 & 2.04 & 1.32 & 1.22 & 1.20 \\
15 & 7.15 & 1.71 & 1.65 & 1.17 & 1.46 & 0.76 & 1.36 & 0.99 & 0.50 & 0.94 \\
\hline
\end{tabular}

All CBF values acquired in the test solutions showed a significant reduction compared to the control group ( $p$-value $=0.001)$. Time in min. CBF in Hz.

\section{Discussion}

Cocaine is a well-known stimulant and local anesthetic. Anesthesia is achieved by binding to sodium channels in peripheral nerve fibers, making them unable to depolarize and form action potentials and thus disrupting signal conduction (28). Its medical use is limited and it has mostly been replaced by its more potent derivates like lidocaine (3). Central effects are caused by blockage of presynaptic monoamine transporters in the CNS, leading to elevated dopamin, serotonin and noradrenaline levels. This results in a short-term awareness increase and loss of impulse control (29). Long-term abuse leads to addiction via various neurobehavioral mechanisms (30).

Today, cocaine is one of the most commonly used recreational drugs (6). Nasal long-term use can lead to damage of local epithelial cells, cartilage and bone (10). Exposing nasal epithelial cells to cocaine was shown to lead to a significant reduction of $\mathrm{CBF}$. This $\mathrm{CBF}$ reducing effect could be attributed to pharmaceutical properties and the above-mentioned mechanical obstruction of cilia by CHCL crystals. Although CHCL has a solubility in water of $714 \mathrm{~g} / 1$ at $25^{\circ} \mathrm{C}$, we found CHCL crystals settling on monitored cell colonies increasing with time and concentration. Crystals were found in samples containing all tested concentrations. This is probably caused by dilution with RPMI instead of water, since RPMI is already saturated with the contained nutrient components.

Since nasal doses in recreational use of cocaine far surpass its solubility (20-100 mg per nostril), mechanical inhibition of the nasal cilia by CHCL crystals is very likely in those cases. Anesthetic solutions for topical application can contain 4 or $10 \%$ CHCL, making a mechanical inhibition less likely but still possible. At the cellular level, the regulation of cilia motility is not fully understood yet. An increase of intracellular calcium $\left(\mathrm{Ca}^{2+}\right)$ levels leads to stimulation of $\mathrm{CBF}$ and is the common endpoint of all known signal pathways. $\mathrm{Ca}^{2+}$ can be mobilized from intracellular stores or transported from outside the cell (31). In vitro exposure of airway epithelia to $\mathrm{Ca}^{2+}$ and Acetylcholin (ACH) leads to an increase in $\mathrm{CBF}(32) \cdot \mathrm{Ca}^{2+}$ can be transported directly into the cell or activate transmembrane

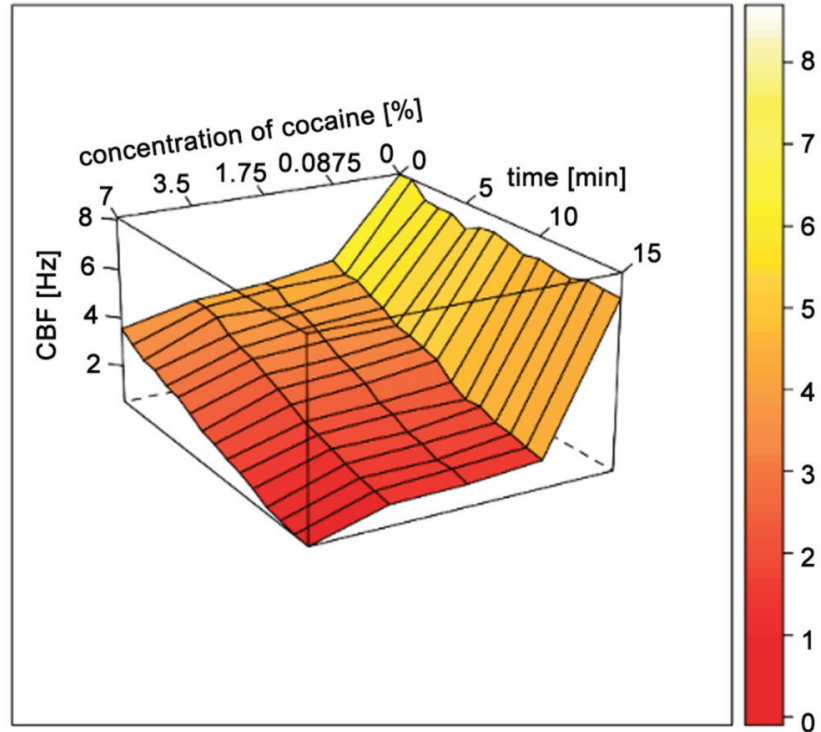

Figure 2. Wireframe surface plot showing changes of ciliary beat frequency $(\mathrm{CBF})$ depending on time and concentration of cocaine hydrochloride (CHCL) solution.

adenylyl cyclases leading to cAMP-pathway activation and CBF increase by Dynein-arm phosphorylation via PKA (33). $\mathrm{ACH}$ triggers muscarinergic $\mathrm{ACH}$ receptors (mACH-R) on the cell membrane causing hydrolyzation and activation of inositol-trisphosphate (IP3) which in turn leads to $\mathrm{Ca}^{2+}$ release from intracellular stores (13). Cocaine interferes in this pathway by antagonizing mACH-R (34).

There are also studies showing a benefit to mucociliary clearance after blocking epithelial sodium channels (ENaC). This effect is accredited to an increased airway hydration (35, 36). While inhibiting voltage-dependent sodium-ion channels in peripheral nerves (37), it is not known whether cocaine blocks ENaC. Overall, this study shows another possible additional mechanism of nasal mucosa damaging by cocaine leading to CIMDL. The role of this mechanism in the pathogenesis of CIMDL remains partly unclear, but it can be 
assumed that disruption of mucociliary clearance via the signal paths described above promotes local toxicity, increases drug exposure time and weakens local immunodefense mechanisms.

This is the first study analyzing the impact of cocaine on CBF with highspeed video-microscopy. Our results help to better understand the pathophysiology and the damage mechanism of intranasal consumption of cocaine. But there are a few limitations which must be considered. Due to the time gap between adding of the CHCL solution and acquiring the first video sequences, there is already a significant reduction of CBF for all CHCL concentrations compared to the control group at $\mathrm{t}=0$.

Cocaine obtained from street vendors for recreational use is rarely pure. Besides pharmacological inactive "fillers" like sugars (e.g. innositol, mannitol, glucose), there is a wide variety of drugs added to mimic the effect of cocaine (e.g. caffeine, lidocaine, levamisole) or alleviate unwanted effects like increased blood pressure, tachycardia and anxiety (e.g. diltiazem, hydroxyzine) (38). This study cannot differentiate if occurrence of CIMDL is promoted by cocaine alone. Additional effects of the cutting agents must be taken into account. A calcium antagonist like diltiazem, for example, is also very likely to reduce CBF even more than CHCL alone.

It also has to be considered that the setup does not allow analysis of the irreversibility of the observed effect. Since the cell clusters where not fixed in the test solutions, it was not possible to wash out the CHCL without moving the cells. Previous studies have shown reversible $\mathrm{CBF}$ reduction with 1.5$20 \%$ CHCL solutions and irreversible CBF reduction between 7-20\% CHCL solutions (23-25). All studies where limited to in vitro testing. It is not known, how long $\mathrm{CBF}$ reduction by cocaine lasts in vivo. Presuming an irreversible $\mathrm{CBF}$ reduction, the effects may last for at least 5 days, which is the observed regeneration time of nasal mucosa after mechanical injury with intact basal cells and basement membrane (39).

\section{Conclusion}

CHCL is a potent inhibitor of CBF in nasal epithelial cells. Beside the other negative effects of cocaine, the associated reduction of mucociliary clearance might contribute to development of the cocaine induced midline destructive lesions including hyposmia, crusting, ulcers, nasal septal perforation and bone erosion.

\section{Conflicts of Interest}

The Authors declare that they have no conflicts of interest.

\section{Authors' Contributions}

Alexander Nastev and Richard Birk conceived and planned the experimental design. Alexander Nastev, Richard Birk, C. Emika Mueller and Daniel Haeussler carried out the experiments. Richard
Birk and Alexander Nastev took lead in writing the article. J. Ulrich Sommer and Richard Birk performed statistical analysis. Alexander Nastev, J. U. Sommer, Wieland Behr, Boris A. Stuck, Emika Mueller, Angela Schell, Benedikt Kramer, Daniel Haeussler and Karl Hoermann contributed to the interpretation of the results, provided critical feedback and improved the article. All Authors carefully read and commented on the article.

\section{Acknowledgements}

The Authors of the present study would like to thank Petra Prohaska for technical support.

\section{References}

1 Gaedcke F: Ueber das erythroxylin, dargestellt aus den blättern des in südamerika cultivirten strauches erythroxylon coca lam. Archiv der Pharmazie 132(2): 141-150, 1855.

2 Koller C: Vorläufige mittheilung über locale anästhesirung am auge. Bericht über die sechzehnte versammlung der ophthalmologischen gesellschaft. Rostock: Adler; pp. 60-63, 1884.

3 Calatayud J and González Á: History of the development and evolution of local anesthesia since the coca leaf. Anesthesiology 98(6): 1503-1508, 2003. PMID: 12766665. DOI: 10.1097/ 00000542-200306000-00031

4 Greinwald JH, Jr. and Holtel MR: Absorption of topical cocaine in rhinologic procedures. Laryngoscope 106(10): 1223-1225, 1996. PMID: 8849789. DOI: 10.1097/00005537-19961000000009

5 Liao BS, Hilsinger RL, Jr., Rasgon BM, Matsuoka K and Adour KK: A preliminary study of cocaine absorption from the nasal mucosa. Laryngoscope 109(1): 98-102, 1999. PMID: 9917048. DOI: $10.1097 / 00005537-199901000-00019$

6 United nations office on drugs and crime, world drug report 2019. United Nations publication Sales No. E.19.XI.8. Available at: https://wdr.unodc.org/wdr2019/prelaunch/WDR19_Booklet_ 4_STIMULANTS.pdf

7 Purdy RE, Julien RM, Fairhurst AS and Terry MD: Effect of carbamazepine on the in vitro uptake and release of norepinephrine in adrenergic nerves of rabbit aorta and in whole brain synaptosomes. Epilepsia 18(2): 251-257, 1977.

8 Tikhonov DB and Zhorov BS: Mechanism of sodium channel block by local anesthetics, antiarrhythmics, and anticonvulsants. J Gen Physiol 149(4): 465-481, 2017. PMID: 28258204. DOI: $10.1085 /$ jgp. 201611668

9 O'Leary ME and Hancox JC: Role of voltage-gated sodium, potassium and calcium channels in the development of cocaineassociated cardiac arrhythmias. Br J Clin Pharmacol 69(5): 427-442, 2010. PMID: 20573078. DOI: 10.1111/j.1365-2125.2010.03629.x

10 Trimarchi M, Bertazzoni G and Bussi M: Cocaine induced midline destructive lesions. Rhinology 52(2): 104-111, 2014. PMID: 24932619. DOI: 10.4193/Rhin13.112

11 Singh MK, Elefteriou $F$ and Karsenty G: Cocaine and amphetamine-regulated transcript may regulate bone remodeling as a circulating molecule. Endocrinology 149(8): 3933-3941, 2008. PMID: 18450969. DOI: 10.1210/en.2008-0109

12 Wiesner O, Russell KA, Lee AS, Jenne DE, Trimarchi M, Gregorini $G$ and Specks U: Antineutrophil cytoplasmic antibodies reacting with human neutrophil elastase as a 
diagnostic marker for cocaine-induced midline destructive lesions but not autoimmune vasculitis. Arthritis Rheum 50(9): 2954-2965, 2004. PMID: 15457464. DOI: 10.1002/art.20479

13 Braiman A and Priel Z: Efficient mucociliary transport relies on efficient regulation of ciliary beating. Respir Physiol Neurobiol 163(1-3): 202-207, 2008. PMID: 18586580. DOI: 10.1016/ j.resp.2008.05.010

14 Satir P and Sleigh MA: The physiology of cilia and mucociliary interactions. Annu Rev Physiol 52: 137-155, 1990. PMID: 2184754. DOI: 10.1146/annurev.ph.52.030190.001033

15 Stannard W and O'Callaghan C: Ciliary function and the role of cilia in clearance. J Aerosol Med 19(1): 110-115, 2006. PMID: 16551222. DOI: $10.1089 /$ jam.2006.19.110

16 Munkholm $\mathrm{M}$ and Mortensen J: Mucociliary clearance: Pathophysiological aspects. Clin Physiol Funct Imaging 34(3): 171-177, 2014. PMID: 24119105. DOI: 10.1111/cpf.12085

17 Robinson $\mathrm{M}$ and Bye PTB: Mucociliary clearance in cystic fibrosis. Pediatr Pulmonol 33(4): 293-306, 2002. PMID: 11921459. DOI: $10.1002 /$ ppul.10079

18 Houtmeyers E, Gosselink R, Gayan-Ramirez G and Decramer M: Regulation of mucociliary clearance in health and disease. Eur Respir J 13(5): 1177-1188, 1999. PMID: 10414423. DOI: 10.1034/j.1399-3003.1999.13e39.x

19 Sisson JH: Alcohol and airways function in health and disease. Alcohol 41(5): 293-307, 2007. PMID: 17764883. DOI: 10.1016/ j.alcohol.2007.06.003

20 Utiyama DM, Yoshida CT, Goto DM, de Santana Carvalho T, de Paula Santos U, Koczulla AR, Saldiva PH and Nakagawa NK: The effects of smoking and smoking cessation on nasal mucociliary clearance, mucus properties and inflammation. Clinics (Sao Paulo) 71(6): 344-350, 2016. PMID: 27438569. DOI: $10.6061 /$ clinics/2016(06)10

21 Abou Alaiwa MH, Reznikov LR, Gansemer ND, Sheets KA, Horswill AR, Stoltz DA, Zabner J and Welsh MJ: Ph modulates the activity and synergism of the airway surface liquid antimicrobials $\beta$-defensin-3 and 11-37 Proc Natl Acad Sci USA 111(52): 18703-18708, 2014. PMID: 25512526. DOI: 10.1073/ pnas.1422091112

22 Dewulf J, Hecq JD, Huvelle S, Godet M, Gillet P, Jamart J and Galanti LM: Long-term stability of cocaine hydrochloride aqueous solution $50 \mathrm{mg} / \mathrm{ml} \mathrm{(5 \% )}$ at room temperature and at 5 degrees $\mathrm{c}+/-3$ degrees $\mathrm{c}$ in glass bottles. Int J Pharm Compd 19(3): 268-270, 2015. PMID: 26714368

23 Coressen $\mathrm{G}$ and Allen C: Cultured human respiratory epithelium: Its use in the comparison of the cytotoxic properties of local anesthetics. Anesthesiology 21(3): 237-243, 1960. PMID: 13812115.

24 Ingels KJ, Nijziel MR, Graamans K and Huizing EH: Influence of cocaine and lidocaine on human nasal cilia. Beat frequency and harmony in vitro. Arch Otolaryngol Head Neck Surg 120(2): 197-201, 1994. PMID: 8297578. DOI: 10.1001/archotol. 1994.01880260067012

25 van de Donk HJM, van Egmond ALM, van den Heuvel AGM, Zuidema $\mathrm{J}$ and Merkus FWHM: The effects of drugs on ciliary motility iii. Local anaesthetics and anti-allergic drugs. Int J Pharm 12(1): 77-85, 1982. DOI: 10.1016/0378-5173(82)90135-1

26 Sommer JU, Gross S, Hörmann K and Stuck BA: Timedependent changes in nasal ciliary beat frequency. Eur Arch Otorhinolaryngol 267(9): 1383-1387, 2010. PMID: 20169353. DOI: $10.1007 / \mathrm{s} 00405-010-1211-5$
27 Thomas B, Rutman A and O'Callaghan C: Disrupted ciliated epithelium shows slower ciliary beat frequency and increased dyskinesia. Eur Respir J 34(2): 401-404, 2009. PMID: 19648518. DOI: $10.1183 / 09031936.00153308$

28 Covino BG: Physiology and pharmacology of local anesthetic agents. Anesth Prog 28(4): 98-104, 1981. PMID: 6949484.

29 Spronk DB, van Wel JH, Ramaekers JG and Verkes RJ: Characterizing the cognitive effects of cocaine: A comprehensive review. Neurosci Biobehav Rev 37(8): 1838-1859, 2013. PMID: 23876288. DOI: 10.1016/j.neubiorev.2013.07.003

30 Bickel WK, Snider SE, Quisenberry AJ, Stein JS and Hanlon CA: Competing neurobehavioral decision systems theory of cocaine addiction: From mechanisms to therapeutic opportunities. Prog Brain Res 223: 269-293, 2016. PMID: 26806781. DOI: 10.1016/bs.pbr.2015.07.009

31 Schmid A and Salathe M: Ciliary beat co-ordination by calcium. Biol Cell 103(4): 159-169, 2011. PMID: 21401526. DOI: 10.1042/BC20100120

32 Do BH, Ohbuchi T, Wakasugi T, Koizumi H, Yokoyama M, Hohchi $\mathrm{N}$ and Suzuki H: Acetylcholine-induced ciliary beat of the human nasal mucosa is regulated by the pannexin- 1 channel and purinergic p2x receptor. Am J Rhinol Allergy, 2018. PMID: 29676177. DOI: $10.1177 / 1945892418770292$

33 Nlend MC, Schmid A, Sutto Z, Ransford GA, Conner GE, Fregien $\mathrm{N}$ and Salathe M: Calcium-mediated, purinergic stimulation and polarized localization of calcium-sensitive adenylyl cyclase isoforms in human airway epithelia. FEBS Lett 581(17): 32413246, 2007. PMID: 17586501. DOI: 10.1016/j.febslet.2007.06.015

34 Carrera MR, Meijler MM and Janda KD: Cocaine pharmacology and current pharmacotherapies for its abuse. Bioorg Med Chem 12(19): 5019-5030, 2004. PMID: 15351386. DOI: 10.1016/ j.bmc.2004.06.018

35 Astrand $\mathrm{AB}$, Hemmerling $\mathrm{M}$, Root J, Wingren C, Pesic J, Johansson E, Garland AL, Ghosh A and Tarran R: Linking increased airway hydration, ciliary beating, and mucociliary clearance through enac inhibition. Am J Physiol Lung Cell Mol Physiol 308(1): L22-32, 2015. PMID: 25361567. DOI: 10.1152/ ajplung.00163.2014

36 Mall MA: Role of cilia, mucus, and airway surface liquid in mucociliary dysfunction: Lessons from mouse models. J Aerosol Med Pulm Drug Deliv 21(1): 13-24, 2008. PMID: 18518828. DOI: $10.1089 /$ jamp.2007.0659

37 Overington JP, Al-Lazikani B and Hopkins AL: How many drug targets are there? Nat Rev Drug Discov 5(12): 993-996, 2006. PMID: 17139284. DOI: 10.1038/nrd2199

38 Broseus J, Gentile N and Esseiva P: The cutting of cocaine and heroin: A critical review. Forensic Sci Int 262: 73-83, 2016. PMID: 26974713. DOI: 10.1016/j.forsciint.2016.02.033

39 Ohashi Y, Nakai Y, Ikeoka H and Furuya H: Regeneration of nasal mucosa following mechanical injury. Acta Otolaryngol Suppl 486: 193-201, 1991. PMID: 1842867. DOI: 10.3109/ 00016489109134996

Received August 22, 2020

Revised September 6, 2020 Accepted September 13, 2020 